Neurosurg Focus 20 (2):E2, 2006

\title{
Cervical spine deformity associated with resection of spinal cord tumors
}

\author{
Daniel R. Fassett, M.D., M.B.A., Randy Clark, M.S., Douglas L. Brockmeyer, M.D., \\ AND MeIC H. SCHMIDT, M.D. \\ Department of Neurosurgery, University of Utah School of Medicine, Salt Lake City, Utah
}

\begin{abstract}
$\checkmark$ Postoperative sagittal-plane cervical spine deformities are a concern when laminectomy is performed for tumor resection in the spinal cord. These deformities appear to occur more commonly after resection of intramedullary spinal cord lesions, compared with laminectomy for stenosis caused by degenerative spinal conditions. Postlaminectomy deformities are most common in pediatric patients with an immature skeletal system, but are also more common in young adults $(<25$ years of age $)$ in comparison with older adults. The extent of laminectomy and facetectomy, number of laminae removed, location of laminectomy, preoperative loss of lordosis, and postoperative radiation therapy in the spine have all been reported to influence the risk of postlaminectomy spinal deformities. When these occur, patients should be monitored closely with serial imaging studies, because a significant percentage will have progressive deformities. These can range from focal kyphosis to more complicated swan-neck deformities. General indications for surgical intervention include progressive deformity, axial pain in the area, and neurological symptoms attributable to the deformity. Surgical options include anterior, posterior, and combined anterior-posterior procedures. The authors have reviewed the literature on postlaminectomy kyphosis as it relates to resection of cervical spinal cord tumors, and they summarize some general factors to consider when treating these patients.
\end{abstract}

KeY WORDS • kyphosis • cervical deformity • intramedullary tumor • laminectomy • children

$\mathrm{C}$ ERVICAL deformities, including swan-neck deformities and cervical kyphosis, do not commonly develop after cervical laminectomy. Nonetheless, this condition is more frequently seen within certain patient populations, such as patients who have undergone a laminectomy to treat intramedullary spinal cord lesions. We have reviewed the literature on postlaminectomy cervical spine deformities and will focus on the biomechanical considerations, incidence, risk factors, and management of these deformities as they relate to resection of cervical spinal cord tumors.

\section{Biomechanical Considerations}

With the normal lordotic curve of the cervical spine, the weight-bearing axis lies posterior to the VBs. As a result, approximately two thirds of the load is carried by the posterior columns. ${ }^{27}$ The loss of the posterior ligamentous and bone elements after cervical laminectomy can shift the weight-bearing axis forward. This results in loss of lordosis and a change to a straight or kyphotic alignment, which moves the weight-bearing axis ventrally to a position in

Abbreviations used in this paper: $\mathrm{MR}=$ magnetic resonance; $\mathrm{VB}=$ vertebral body. front of the VBs. As this kyphotic deformity progresses, the anterior column tends to be compressed and the posterior columns are placed under tension (Fig. 1). The trauma of surgery weakens the posterior tension band, decreasing its ability to withstand the forces needed to maintain alignment. As a result, the kyphotic deformity propagates further stress and the deformity progresses. ${ }^{13,28,42}$

The biomechanics of sagittal-plane cervical deformities have been studied in the laboratory by many investigators. Goel, et al., ${ }^{12,13}$ reported a $10 \%$ increase in flexion-extension motion after laminectomy in a cadaveric model, and they hypothesized that this immediate increase in motion could lead to subsequent instability. In a biomechanical comparison of laminectomy and laminoplasty in a cadaveric model, Nowinski, et al., ${ }^{25}$ found that cervical laminectomy with more than $25 \%$ facetectomy significantly increased motion in flexion-extension, lateral bending, and axial torsion, whereas laminoplasty resulted in much less instability.

Saito, et al., ${ }^{36}$ used a finite-element computer analysis to simulate cervical spine biomechanics in the setting of a C3-7 laminectomy. Using different values for elastic modulus, they were able to model the effects of laminectomy in children and adults, and they reported that an increasing elastic modulus (decreased flexibility), as would be seen with aging, changed the spinal deformities from a swan-neck type to a kyphotic one, and then to a straight- 
ening deformity. In summary, they reported that aging, which is accompanied by an increasing elastic modulus, reduced the likelihood and severity of postlaminectomy cervical spine deformities.

Raynor, et al. ${ }^{32}$ were among the first to evaluate the biomechanical ramifications of laminectomy and facetectomy in the cervical spine. They found that the shear strength of a cervical motion segment decreased significantly when more than $50 \%$ of the facet joint was resected. Zdeblick, et al. ${ }^{48}$ in a similar but more elaborate cadaveric study, also noted instability after resection of more than $50 \%$ of the facet joint. On further investigation, they found that instability occurred after more than $50 \%$ resection of the facet capsule alone, and that therefore the integrity of the facet capsule might be the most important factor in stability after laminectomy. ${ }^{46}$

Nolan and Sherk ${ }^{24}$ tested the extensor musculature forces on the cervical spine and hypothesized that this musculature, specifically the semispinalis cervicis and semispinalis capitis, helps prevent deformity after laminectomy by acting to keep the cervical spine and head in an extended position. Disruption and weakness of the extensor musculature caused by muscle detachment to attain exposure could possibly promote sagittal-plane deformity. Therefore, these authors recommend preservation and reattachment of the extensor musculature as much as possible.

\section{Postlaminectomy Cervical Spine Deformities}

\section{General Incidence}

Cervical laminectomy is a common procedure that is normally accomplished with few immediate complications. The most common indications for this procedure include cervical stenosis in association with advanced spondylosis, centrally herniated discs, or ossification of the posterior longitudinal ligaments. For a procedure that is performed so frequently, laminectomy rarely results in deformities, but some conflicting data exist. ${ }^{19}$ It is generally accepted that adults with normal preoperative spine alignment and no instability who undergo cervical laminectomy rarely experience kyphotic deformity. ${ }^{5,15,35,40}$

One contradictory study by Kaptain, et al. ${ }^{16}$ noted a much higher incidence of postlaminectomy cervical spine deformity. In this study, the authors evaluated 46 patients who underwent laminectomy to treat cervical spondylotic myelopathy. Their study was based on a review of pre- and postoperative plain $\mathrm{x}$-ray films obtained during a mean follow up of 4 years. The investigators noted a $14 \%$ incidence of postoperative kyphosis in patients who initially had a lordotic cervical spine, and more than twice the incidence $(30 \%)$ in patients whose spine was straight $\left(<4^{\circ}\right.$ of lordosis or kyphosis) preoperatively. The authors emphasized that their procedure involved removal of the lamina and only the medial one fourth of the facets. Similar results with high deformity rates can be found in the literature on cervical laminoplasty. Although many investigators have theorized that laminoplasty may reduce the risk of deformity in comparison with laminectomy, high rates of deformity were found in a metaanalysis of the laminoplasty literature, with a worsening of cervical alignment noted in $35 \%$ of patients and a postoperative kyphosis developing in $10 \% .31$
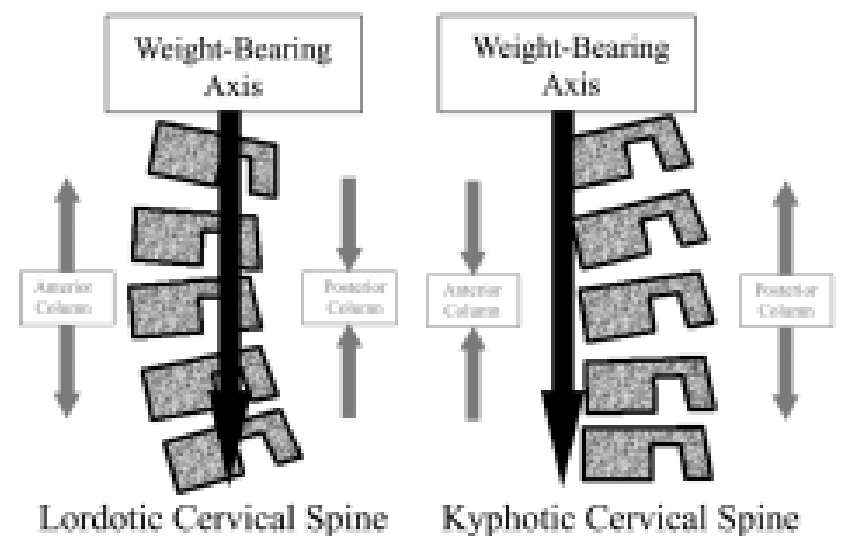

FIG. 1. Schematic drawings showing lordosis and kyphosis in the cervical spine. Kyphosis tends to be a self-propagating condition because the deformity causes the weight-bearing axis in the cervical spine to move to a more ventral position in front of the VBs. In a normal lordotic cervical spine, the weight-bearing axis lies posterior to the VBs, with the anterior spinal column under tension and the posterior elements under compression. With kyphosis, the anterior spinal column is under compression and the posterior elements are under tension. If the integrity of the posterior tension band is violated, as in the case of laminectomy, the structural support of the cervical spine cannot sufficiently resist the biomechanical forces promoting progression of the kyphotic deformity.

\section{Risk Factors Associated With Postlaminectomy Deformity}

Multiple risk factors are associated with cervical spine deformity after laminectomy, including age (pediatric compared with adult), $17,19,21,23,29,43$ extent of laminectomy and facetectomy, ${ }^{13,17,46,48}$ number of laminae removed, ${ }^{17,29}$ location of laminectomy (upper, middle, or lower cervical spine), ${ }^{3,17,43}$ preoperative loss of lordosis, ${ }^{16,17}$ pathological condition in the intramedullary spinal cord, ${ }^{16,19,21,31,39}$ and radiation treatment in the spine. ${ }^{8,10,18,21,33,39,41}$ Younger age appears to be the most significant risk factor for the development of postlaminectomy cervical spine deformities. Pediatric patients with an immature skeletal system are at the greatest risk for deformity, followed by young adults $(<25$ years of age), who also appear to have an elevated risk compared with older adults. ${ }^{29,44}$ In pediatric patients, postlaminectomy deformities can occur at any spinal level (cervical, thoracic, or lumbar), but are especially common in the cervical spine (Fig. 2). ${ }^{8,43,44}$

Resection of spinal cord tumors is one of the more common reasons to perform a laminectomy in children. Children who undergo multilevel laminectomies for intraspinal tumors (intra- and extramedullary) have a high incidence of spinal column deformity, with reported rates between 24 and $100 \% .4,6,8,11,14,17,20,21,39,44$ The intraspinal lesions may be a confounding factor; intraspinal tumors are often associated with spinal deformities, even without surgery. ${ }^{21}$

In an effort to remove this confounding variable, Yasuoka, et al., ${ }^{44}$ studied the incidence of postlaminectomy deformities in children and young adults who underwent laminectomy for conditions that did not in themselves cause deformities. The authors evaluated two groups of patients based on age $(<15$ years and 15-25 years of age) and found that the younger patients had higher rates of 


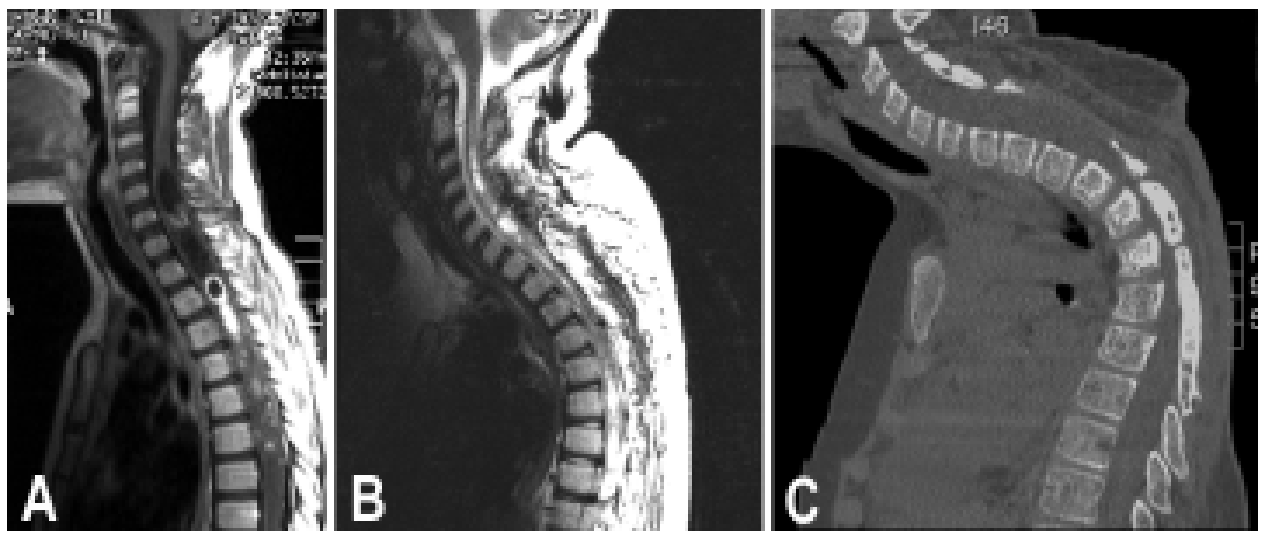

FIG. 2. Preoperative and postoperative neuroimages obtained in an 8-year-old boy with a spinal cord oligodendroglioma at the cervicothoracic junction who underwent four resections of his tumor with laminectomy. A: The initial sagittal MR image demonstrates the spinal cord tumor extending from C-3 to T-2 and a normal cervical lordosis. B: After two tumor resections in 12 months, a kyphosis $\left(50^{\circ}\right)$ developed at the cervicothoracic junction, as revealed on the sagittal $\mathrm{T}_{2}$-weighted MR image. C: Sagittal computerized tomography reconstruction image demonstrating that his kyphotic deformity continued to progress to $90^{\circ}$ over the next 16 months, after two further resections with laminectomy from $\mathrm{C}-4$ to $\mathrm{T}-3$ were performed.

postoperative deformities; $46 \%$ of the 26 younger patients suffered spinal deformities, whereas only $6 \%$ of the 32 older patients had these complications. This series included patients with cervical, thoracic, and lumbar lesions. In individuals treated with cervical decompression, the authors reported that $100 \%$ of the 12 patients younger than 15 years of age suffered deformity after cervical laminectomy. Other series of cervical spine laminectomies performed for reasons other than tumor removal confirm high rates of postoperative deformities in pediatric patients. ${ }^{4}$

The cause of the increased incidence of spinal deformity after laminectomy in children is likely multifactorial. Ligamentous structures in the pediatric spine are more lax than those in adults. In addition, the orientation of the facet complex of the cervical spine is more horizontal in children than the vertically shingled facet complex seen in adults. The combination of these two factors allows for less stability and, with the right set of circumstances (such as loss of the posterior tension band after laminectomy), sagittal-plane deformities can occur more easily. The growing vertebral column is another compounding factor; once deformities start, they tend to progress in the presence of a growing spine because of abnormal growth in association with the changes in spinal biomechanics. In the circumstance of an immature spine with growth plates, treatment with spinal radiation can also compound the deformity by creating asymmetrical growth patterns. . $7,7,39,43$

Spinal cord lesions alone, without surgical destabilization, can cause spinal deformities in both adults and children (Fig. 3)..$^{21,37,39}$ Some authors have theorized that involvement of the anterior horn cells causes muscle denervation and weakness, which leads to the spinal deformity. ${ }^{9,37}$ Others have speculated that a flexed posture, in cases of intradural lesions, tends to open the spinal canal and may relieve symptoms; however, this promotes a kyphotic deformity. Lunardi, et al., ${ }^{21}$ noted preoperative spinal deformities in nine of 25 pediatric patients with intramedullary spinal cord tumors. Tachdjian and Matson ${ }^{39}$ found preexisting scoliosis in $27 \%$ of pediatric patients with spinal tumors (both intradural and extradural lesions), and they found preexisting kyphosis in 15\%. Preexisting deformity is a risk factor for progressive deformity after laminectomy for tumor resection. ${ }^{16,17}$ Kaptain, et al., ${ }^{16}$ reported that the risk of postoperative deformities doubled when the spine was deformed preoperatively.

The location of the laminectomy in the cervical spine also appears to be a significant risk factor for development of deformity. Patients who undergo laminectomy at highstress areas like the craniocervical and cervicothoracic junctions will probably have a higher risk for postoperative spinal deformities. The increased risk at the craniocervical junction has been documented by several authors., 317,43

The length (number of laminae removed) and extent (degree of facet resection) of laminectomy have both been reported to increase the risk of postoperative deformities, although the literature is inconclusive. Katsumi, et al., ${ }^{17}$ reported a $46 \%$ incidence of postlaminectomy cervical kyphosis in patients in whom four or more laminae were removed, which was four times the risk for patients in whom fewer than four were removed. Other authors have reported no correlation between the incidence of kyphosis and the number of laminae removed. ${ }^{4,44}$ Most of the literature regarding degree of facet resection is based on biomechanical studies conducted in cadaveric specimens, which may not accurately model the physiology in a living human spine. Large-scale clinical studies confirming the results of the laboratory studies are lacking, although Katsumi, et al., ${ }^{17}$ reported higher rates of instability when the facet joints were destroyed by tumor or surgery in a series of eight patients.

Deformity of the spine after radiation therapy has been documented experimentally and clinically in children and adults. The effects of radiation appear to be more profound on the immature spine because of the asymmetrical growth patterns that result. Even relatively low doses of radiation have been associated with spinal deformities, and the incidence of spinal deformity has been reported to be as high as $60 \%{ }^{2,10,18,26,30,33,34,41}$ 


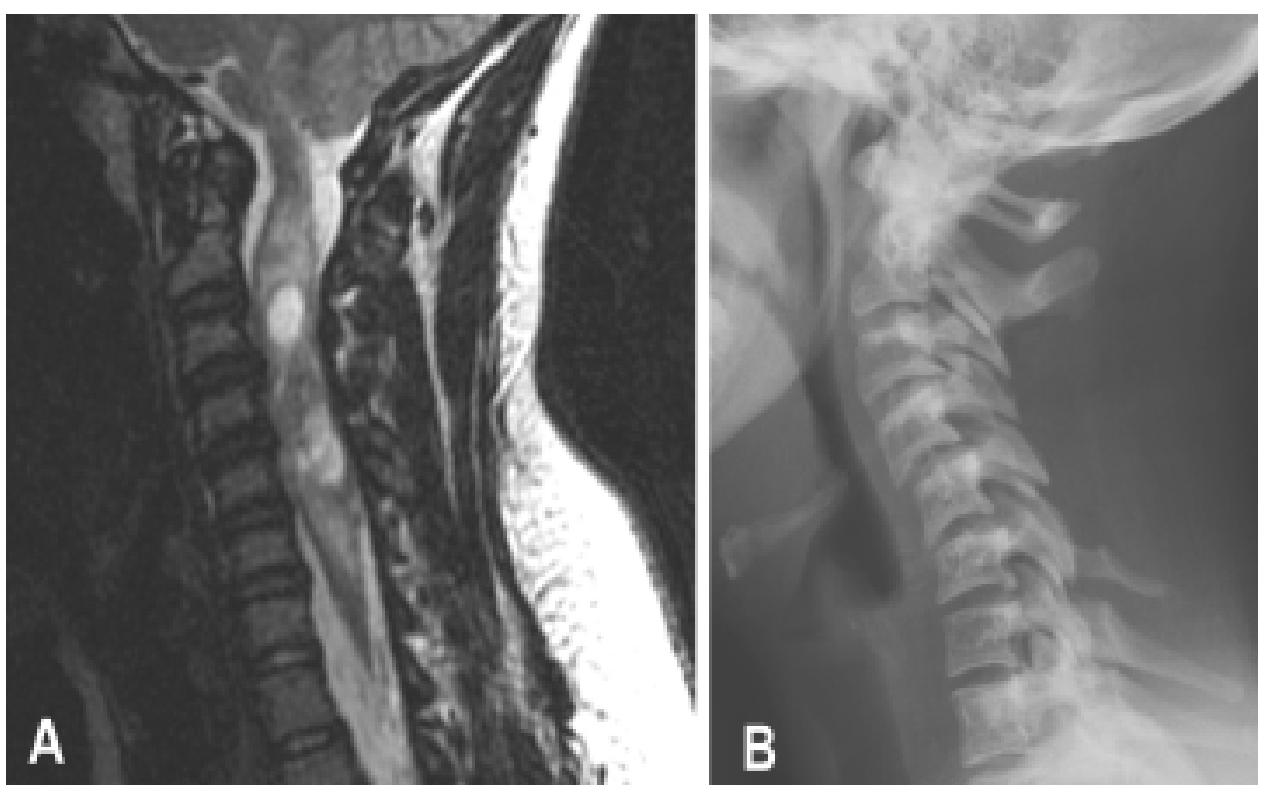

FIG. 3. Neuroimages obtained in a 25-year-old woman who underwent C3-5 laminectomy for resection of intramedullary ependymoma and in whom postoperative kyphosis developed within 1 month of surgery. A: Preoperative sagittal $\mathrm{T}_{2}$-weighted MR image demonstrating intramedullary spinal cord tumor and a straight sagittal alignment of the cervical spinal column. B: Lateral x-ray film of the cervical spine obtained 1 month postsurgery, showing $20^{\circ}$ kyphosis between C-4 and C-6.

The cumulative number of risk factors present likely has an impact on the risk of progressive deformity after laminectomy. Katsumi, et al., ${ }^{17}$ found that patients in whom instability did not develop had a mean of 1.2 risk factors, patients in whom instability developed had a mean of 2.5 risk factors, and patients who needed surgical stabilization had at least 3 risk factors. Among the risk factors evaluated in this study were the patient's age at operation, preoperative spinal curvature in neutral position, number of laminae removed, C-2 laminectomy, and destruction of facet joints. In the situation of laminectomy for tumor resection, one risk factor (intraspinal tumor) is already present, and the surgeon should be diligent in considering other risk factors for postlaminectomy instability, because this may influence the surgical approach.

\section{Management and Treatment}

\section{Preoperative Evaluation}

We recommend that plain $\mathrm{x}$-ray films of the cervical spine (anteroposterior and lateral) be obtained preoperatively to serve as a baseline for future comparisons and to rule out a preexisting deformity that could change the initial surgical management. Patients with preoperative loss of lordosis are counseled that they have a higher risk of postoperative deformity, and that they may need an additional stabilization procedure if deformity occurs. In the rare case of a patient with preoperative kyphosis, we would consider performing a stabilization procedure at the time of initial laminectomy for tumor resection. It is unclear how long asymptomatic patients should undergo follow-up evaluations for possible deformity. Radiographic evidence of deformities can occur as soon as the 1st postoperative day, but it can also present years after decompressive sur- gery. ${ }^{21,37,44}$ It has been our practice to screen high-risk patients (younger individuals and those with loss of lordosis) with plain lateral x-ray films at their follow-up visits for 5 years. Other authors have used a similar protocol for the screening of high-risk patients. ${ }^{44}$

\section{Measures to Reduce Risk of Postlaminectomy Deformity}

The risk of postlaminectomy kyphosis should always be considered before approaching tumors in the spinal canal for resection, especially in higher-risk patients such as children and young adults. Efforts should be made to limit facet resection and the number of laminae removed without compromising the surgical exposure needed for tumor resection. A general consensus advises removing no more than $50 \%$ of the medial facet complex..$^{9,32,37,48}$ It has been our practice to leave the facets intact when possible and to use a meticulous technique to preserve the facet capsules when performing the muscle detachment. We cannot stress enough that the surgical exposure needed to address the intraspinal lesion safely takes precedence and should not be compromised with concerns for spinal stability.

In pediatric patients, in whom the skeletal system is not mature, we often use laminoplasty in the hope of reducing the risk of postlaminectomy deformities. Investigators reporting biomechanical studies conducted in the laboratory have suggested that laminoplasty may produce less instability, but clinical studies provide only marginal data supporting this practice. $8,22,25,38,45$

For patients with a preexisting spinal deformity, fusion should be considered at the time of tumor resection to prevent postoperative progression of the deformity. No firm guidelines have been developed for this practice of prophylactic fusion to prevent progression of deformity, but 


\section{Cervical kyphosis after spinal cord tumor resection}
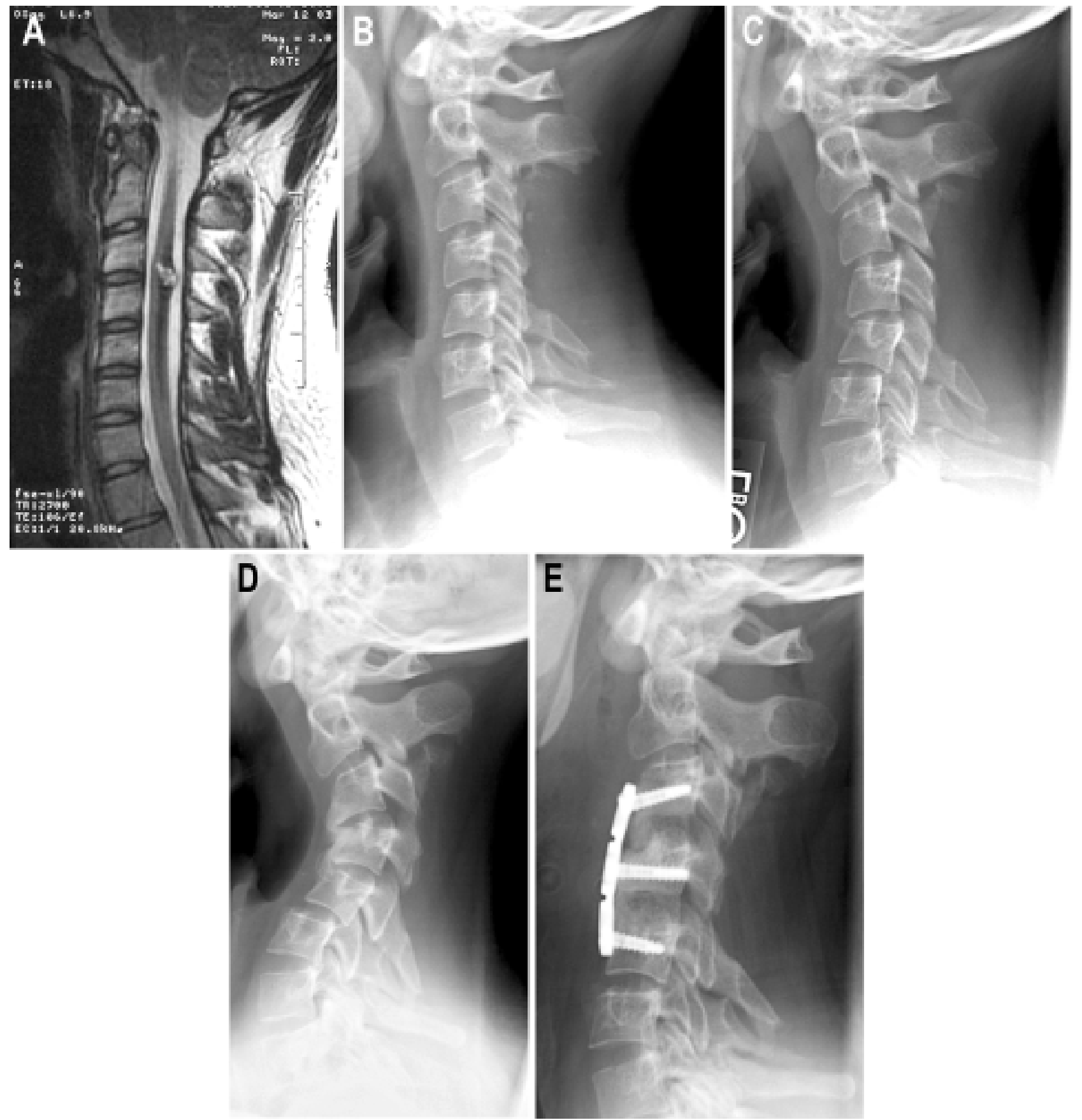

FIG. 4. Preoperative neuroimage and postoperative radiographs obtained in a 24-year-old man who presented with progressive neck pain and upper-extremity pain and numbness. A spinal cord cavernoma was found at C3-4, and he underwent resection with a C3-4 laminectomy. Postoperatively, the patient was noted to have progressive kyphosis on serial radiographs. He had no symptoms related to the deformity for 14 months after his initial surgery, but eventually neck pain and early myelopathic symptoms developed in his upper extremities because of spinal cord compression. His deformity was treated with multilevel anterior cervical discectomy and fusion from C-3 to C-5. He maintained his deformity correction and attained documented fusion 6 months postsurgery. A: Preoperative MR image demonstrating a spinal cord cavernoma at C3-4 and a normal lordotic alignment. B: Lateral x-ray film obtained 1 month postsurgery, showing a mild kyphosis at C4-5. C: Lateral x-ray film obtained 3 months postsurgery, showing an early swan-neck deformity with kyphosis in the upper and accentuated lordosis in the lower cervical spine. D: Lateral x-ray film obtained 16 months after the initial surgery, showing a severe swan-neck deformity. E: Follow-up lateral x-ray film obtained 3 months after anterior cervical discectomy and fusion from C-3 to C-5. 
we would consider all risk factors and counsel the patient accordingly. We have also occasionally used external orthosis with cervical collars in patients we considered to be at high risk, but we have no firm evidence to support this practice.

\section{Surgical Options to Treat Postlaminectomy Deformity}

When postoperative deformities occur, we recommend close observation with serial neuroimages, because a significant percentage of these conditions will continue to progress. In these situations we recommend surgical intervention for stabilization. In the vast majority of cases, the deformity is a sagittal imbalance with either focal kyphosis or a more complex swan-neck type, which can be treated with anterior or posterior stabilization procedures. ${ }^{4,37,47}$ Flexion and extension x-ray films can be helpful in assessing the flexibility of the deformity; those that move with flexion and extension may benefit from preoperative traction for reduction. Fixed deformities that do not move because of ankylosis will require a surgical release at the ankylosed segment before correction, and this may dictate the approach taken. ${ }^{1}$

For cases of focal kyphosis, we prefer anterior cervical discectomy and fusion with plate placement. It is our experience that a better anatomical correction, with restoration of lordosis, can be made via an anterior approach than can be made with posterior procedures. Front-back combined stabilization procedures may be used for severe cases of kyphosis. Swan-neck deformities are much more complex in terms of surgical stabilization. An anterior procedure alone, with either multilevel discectomy and fusion (Fig. 4) or corpectomy with strut grafts, can accomplish reduction of alignment and stabilization. Restoring the sagittal balance with an anterior procedure alone, however, can be technically challenging.

Another option to treat swan-neck deformity is a frontback-front procedure, wherein the initial anterior multilevel discectomies or corpectomies are performed to release the anterior elements. ${ }^{47}$ The anterior wound is then closed and the patient is repositioned prone. With the anterior elements released, a reduction in the sagittal alignment with restoration of lordosis can be accomplished with the patient prone. Placement of posterior instrumentation can also be used to help restore sagittal alignment and stabilize the spine. After the posterior surgical wound is closed, the patient is returned to the supine position and the anterior surgical wound is reopened. Bone grafting is performed to restore the integrity of the anterior column and optimize the likelihood of fusion. Anterior plate placement is optional with a front-back-front approach, but is preferred in our practice because it provides additional stabilization.

\section{Conclusions}

Postlaminectomy cervical spine deformities can be quite common in certain patient populations, such as those who have undergone laminectomy for tumor resections. Several risk factors associated with postlaminectomy deformities should be considered by the surgeon before performing laminectomy. We recommend that pre- and postoperative neuroimaging be performed to screen for deformities, and we often continue this screening for years, depending on the risk factors associated with each case. If a mild defor- mity is found, we follow the patient more closely for progression. Severe deformities are treated with surgical stabilization. The characteristics of each specific deformity (focal kyphosis compared with swan-neck, and fixed compared with flexible deformities) will dictate the surgical approach taken. Anterior, posterior, and front-back procedures all can be used to treat these conditions.

\section{References}

1. Albert TJ, Vacarro A: Postlaminectomy kyphosis. Spine 23: 2738-2745, 1998

2. Arkin AM, Simon N: Radiation scoliosis; an experimental study. J Bone Joint Surg Am 32:396-401, 1950

3. Aronson DD, Kahn RH, Canady A, et al: Instability of the cervical spine after decompression in patients who have ArnoldChiari malformation. J Bone Joint Surg Am 73:898-906, 1991

4. Bell DF, Walker JL, O'Connor G, et al: Spinal deformity after multiple-level cervical laminectomy in children. Spine 19: 406-411, 1994

5. Bishara SN: The posterior operation in treatment of cervical spondylosis with myelopathy: a long-term follow-up study. J Neurol Neurosurg Psychiatry 34:393-398, 1971

6. Boersma G: Verkrommingen van de wer Velkolom na laminectomieen bij kinderen. Amsterdam: Born NV Uitgeversmaatschappij, 1969

7. Bradford DS, Moe JH, Montalvo FJ, et al: Scheuermann's kyphosis. Results of surgical treatment by posterior spine arthrodesis in twenty-two patients. J Bone Joint Surg Am 57: 439-448, 1975

8. de Jonge T, Slullitel H, Dubousset J, et al: Late-onset spinal deformities in children treated by laminectomy and radiation therapy for malignant tumors. Eur Spine J 14:765-771, 2005

9. Epstein JA: The surgical management of cervical spinal stenosis, spondylosis, and myeloradiculopathy by means of the posterior approach. Spine 13:864-869, 1988

10. Evans AE, Norkool P, Evans I, et al: Late effects of treatment for Wilms' tumor. A report from the National Wilms' Tumor Study Group. Cancer 67:331-336, 1991

11. Fraser RD, Paterson DC, Simpson DA: Orthopaedic aspects of spinal tumors in children. J Bone Joint Surg Br 59:143-151, 1977

12. Goel VK, Clark CR, Harris KG, et al: Evaluation of effectiveness of a facet wiring technique: an in vitro biomechanical investigation. Ann Biomed Eng 17:115-126, 1989

13. Goel VK, Clark CR, Harris KG, et al: Kinematics of the cervical spine: effects of multiple total laminectomy and facet wiring. J Orthop Res 6:611-619, 1988

14. Haft H, Ransohoff J, Carter S: Spinal cord tumors in children. Pediatrics 23:1152-1159, 1959

15. Jenkins DH: Extensive cervical laminectomy. Long-term results. Br J Surg 60:852-854, 1973

16. Kaptain GJ, Simmons NE, Replogle RE, et al: Incidence and outcome of kyphotic deformity following laminectomy for cervical spondylotic myelopathy. J Neurosurg 93 (Suppl 2): 199-204, 2000

17. Katsumi Y, Honma T, Nakamura T: Analysis of cervical instability resulting from laminectomies for removal of spinal cord tumor. Spine 14:1171-1176, 1989

18. Katzman H, Waugh T, Berdon W: Skeletal changes following irradiation of childhood tumors. J Bone Joint Surg Am 51: 825-842, 1969

19. Lonstein JE: Post-laminectomy kyphosis. Clin Orthop Relat Res 128:93-100, 1977

20. Lonstein JE, Winter RB, Moe JH, et al: Post-laminectomy spine deformity. J Bone Joint Surg Am 58:727, 1976

21. Lunardi P, Licastro G, Missori P, et al: Management of intra- 
medullary tumors in children. Acta Neurochir (Wien) 120: 59-65, 1993

22. Meyer NJ, Flatley TJ, Dunn DD: Superiorly based laminoplasty in children: average 6.8-year follow-up of 21 patients. J Spinal Disord Tech 16:156-162, 2003

23. Mikawa Y, Shikata J, Yamamuro T: Spinal deformity and instability after multilevel cervical laminectomy. Spine 12:6-11, 1987

24. Nolan JP Jr, Sherk HH: Biomechanical evaluation of the extensor musculature of the cervical spine. Spine 13:9-11, 1988

25. Nowinski GP, Visarius H, Nolte LP, et al: A biomechanical comparison of cervical laminaplasty and cervical laminectomy with progressive facetectomy. Spine 18:1995-2004, 1993

26. Ogilvie J: Spine deformity following radiation therapy, in Lonstein JE, Bradford DS, Winter RB, et al (eds): Moe's Textbook of Scoliosis and Other Spinal Deformities, ed 3. Philadelphia: WB Saunders, 1995, pp 541-547

27. Pal GP, Sherk HH: The vertical stability of the cervical spine. Spine 13:447-449, 1988

28. Panjabi MM, White AA III, Johnson RM: Cervical spine mechanics as a function of transection of components. J Biomech 8:327-336, 1975

29. Papagelopoulos PJ, Peterson HA, Ebersold MJ, et al: Spinal column deformity and instability after lumbar or thoracolumbar laminectomy for intraspinal tumors in children and young adults. Spine 22:442-451, 1997

30. Peterson HA: Iatrogenic Spinal Deformities, in Weinstein SL (ed): The Pediatric Spine: Principles and Practice, ed 1. New York: Raven Press, 1994, pp 651-654

31. Ratliff JK, Cooper PR: Cervical laminoplasty: a critical review. J Neurosurg 98 (3 Suppl):230-238, 2003

32. Raynor RB, Pugh J, Shapiro I: Cervical facetectomy and its effect on spine strength. J Neurosurg 63:278-282, 1985

33. Riseborough EJ: Irradiation induced kyphosis. Clin Orthop Relat Res 128:101-106, 1977

34. Riseborough EJ, Grabias SL, Burton RI, et al: Skeletal alterations following irradiation for Wilms' tumor: with particular reference to scoliosis and kyphosis. J Bone Joint Surg Am 58: 526-536, 1976

35. Rogers L: The treatment of cervical spondylitic myelopathy by mobilisation of the cervical cord into an enlarged spinal canal. J Neurosurg 18:490-492, 1961

36. Saito T, Yamamuro T, Shikata J, et al: Analysis and prevention of spinal column deformity following cervical laminectomy. I. Pathogenetic analysis of postlaminectomy deformities. Spine 16:494-502, 1991
37. Sim FH, Svien HJ, Bickel WH, et al: Swan-neck deformity following extensive cervical laminectomy. A review of twentyone cases. J Bone Joint Surg Am 56:564-580, 1974

38. Spiegel DA, Loder RT, Alley KA, et al: Spinal deformity following selective dorsal rhizotomy. J Pediatr Orthop 24: 30-36, 2004

39. Tachdjian MO, Matson DD: Orthopaedic aspects of intraspinal tumors in infants and children. J Bone Joint Surg Am 47: 223-248, 1965

40. Teng P: Spondylosis of the cervical spine with compression of the spinal cord and nerve roots. J Bone Joint Surg Am 42: 392-407, 1960

41. Thomas PR, Griffith KD, Fineberg BB, et al: Late effects of treatment for Wilms' tumor. Int J Radiat Oncol Biol Phys 9: 651-657, 1983

42. White AA III, Panjabi MM, Thomas CL: The clinical biomechanics of kyphotic deformities. Clin Orthop Relat Res 128: 8-17, 1977

43. Yasuoka S, Peterson HA, Laws ER Jr, et al: Pathogenesis and prophylaxis of postlaminectomy deformity of the spine after multiple level laminectomy: difference between children and adults. Neurosurgery 9:145-152, 1981

44. Yasuoka S, Peterson HA, MacCarty CS: Incidence of spinal column deformity after multilevel laminectomy in children and adults. J Neurosurg 57:441-445, 1982

45. Yeh JS, Sgouros S, Walsh AR, et al: Spinal sagittal malalignment following surgery for primary intramedullary tumors in children. Pediatr Neurosurg 35:318-324, 2001

46. Zdeblick TA, Abitbol JJ, Kunz DN, et al: Cervical stability after sequential capsule resection. Spine 18:2005-2008, 1993

47. Zdeblick TA, Bohlman HH: Cervical kyphosis and myelopathy. Treatment by anterior corpectomy and strut-grafting. J Bone Joint Surg Am 71:170-182, 1989

48. Zdeblick TA, Zou D, Warden KE, et al: Cervical stability after foraminotomy. A biomechanical in vitro analysis. J Bone Joint Surg Am 74:22-27, 1992

Manuscript received December 15, 2005.

Accepted in final form January 10, 2006.

Address reprint requests to: Meic H. Schmidt, M.D., Department of Neurosurgery, University of Utah School of Medicine, 30 North 1900 East, Suite 3B409, Salt Lake City, Utah 84132. email: meic.schmidt@hsc.utah.edu. 